\title{
Assessing Knowledge Retention in Construction Organisations: Cases from the UAE
}

\author{
Mohammed Arif, (University of Salford, UK) \\ Malik Khalfan, (RMIT University, Australia) \\ James H. Barnard, (Apex Operations Group, USA) \\ Nathan A. Heller, (Tarleton State University, USA)
}

\begin{abstract}
The purpose of this paper is to present different issues facing the problem of knowledge retention by construction sector companies in the UAE. Existing framework in the area of knowledge retention has been used to assess three large construction consultancies in the UAE. The case study methodology used in this paper highlights some key issues in the area of knowledge retention in the UAE. Based on the analysis of the knowledge retention system the major drivers for its successful implementation are prevalence of a culture of sharing knowledge, reward and recognition for sharing knowledge, a technology platform that can accommodate multi formats of files, awareness of knowledge retention system and its benefits among its employees, and top management support. The paper presents three case studies and draws conclusions about the UAE construction sector. Although the three companies are large companies, there are several Small and Medium sized Enterprise (SME) operating in the construction sector in the UAE. Future researchers need to look at these SMEs. Through the three case studies, several issues related to the implementation of robust knowledge retention practices have been identified and highlighted for the UAE construction sector.
\end{abstract}

Keywords: Knowledge Retention, Knowledge Management, Organisational Culture, Knowledge Retrieval, Knowledge Leakage, Knowledge Sharing

\section{Introduction}

Knowledge has become widely recognised and accepted as a valuable organisational resource in the business community. Nowadays, companies are facing an environment characterized by levels of complexity, globalisation and dynamism. Furthermore, the dynamic global business market is distinguished by the rapid growth in the construction industry sector; effects of globalization and various world trade agreements have created a revolution and intense competition in the business environment. Given the competition, retention of both the workforce and the knowledge they possess has become a big challenge for corporations worldwide. People retire, find better jobs, or take a break from work, and what leaves with them is their knowledge. With the ongoing globalisation, and competition, organisations quite regularly poach on workforces of each other. With better offers from competition, it is not easy to hold on to your workforce, and that is a fact one has to live with. However, the blow of losing the employee might be softened a little bit, if the knowledge of the departing employee is retained. This paper presents three case studies of construction consultancies in the UAE, which throw light on practices that can potentially help retain some knowledge in the organisation. The following section discusses a framework to assess processes that constitute a knowledge retention system. The paper then discusses three case studies from construction consultancies in the UAE. It is followed by a section that analyses the cases and presents some best practices. The last section summarizes the findings and concluding remarks of the cases. 


\section{Background and Literature Review}

Gurteen (1998) defined Knowledge Management (KM) as "an emerging set of organisational design and operational principles, processes, organisational structures, applications and technologies that helps knowledge employees dramatically leverage their creativity and ability to deliver business value". Alavi and Leidner (2001) defined knowledge management (KM) as the systematic process of acquiring, organising, and communicating (knowledge sharing) knowledge (both tacit and explicit) of organisational members so that others may make use of it to be more effective and productive. Similarly, Egbu (2006) define it as a process that creates, shares, distributes and uses the knowledge in the organisation. Within the construction context, the KM process has been perceived as the combination of a series of activities for identifying, capturing, sharing and using knowledge. $\mathrm{KM}$ is a widely accepted success factors for organisations dealing with complex tasks. One of the major challenges for organisations is to manage knowledge assets for the purpose of gaining competitive advantage in every sector of industry including the construction sector (Fong and Choi, 2009). Kamara et al. (2002) pointed out that KM strategies can help to avoid the repetition of similar mistakes from past work and therefore improve work efficiency. In other words, KM strategies can avoid additional effort, reduce the time spent and save money.

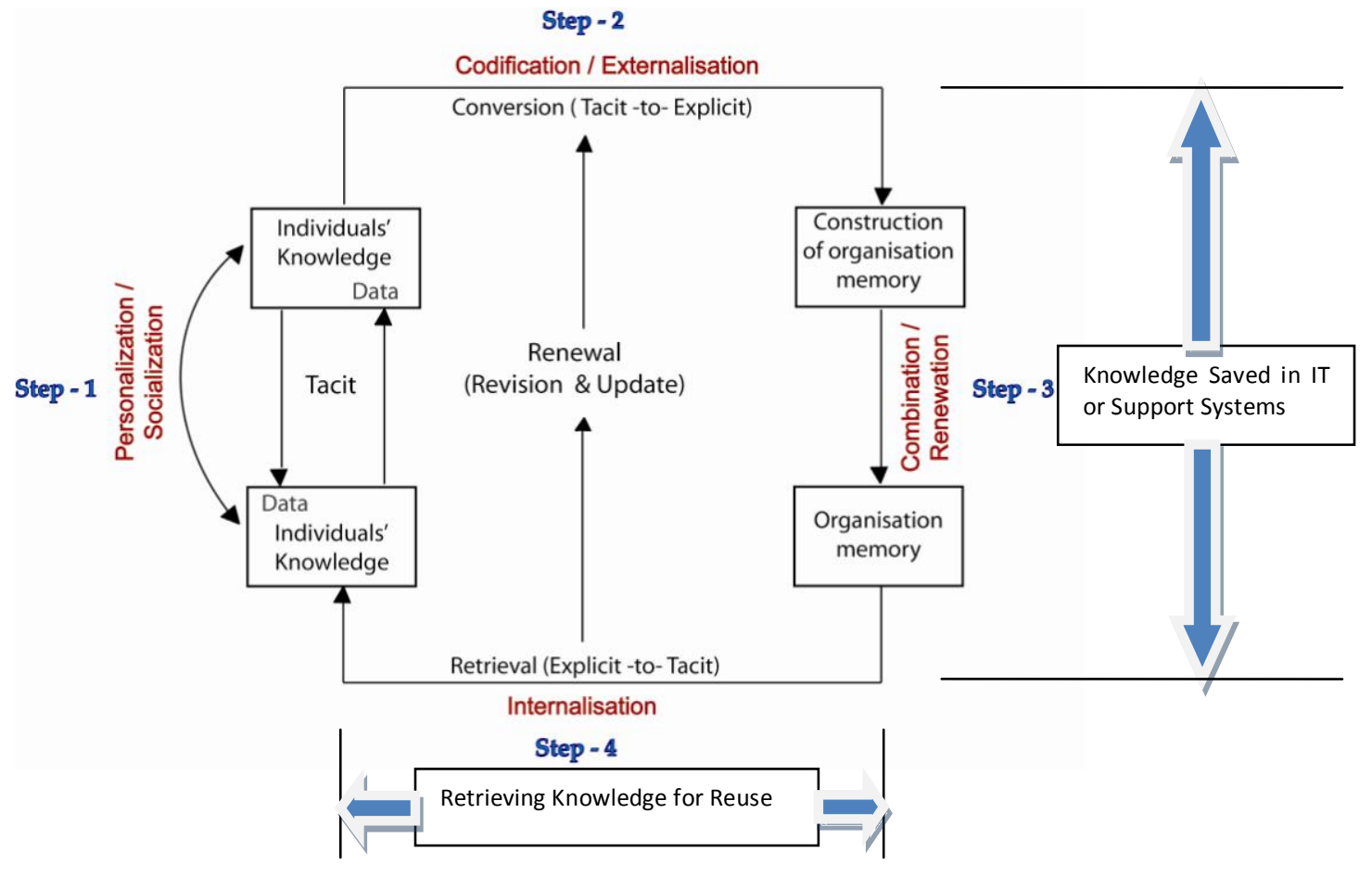

Figure 1 The Knowledge Retention Model

The main KM process can be classified into four sub-processes; creation or acquisition, sharing/transfer, retention or storing, usage/application (Alavi and Leidner, 2001; Kim and Lee, 2010). Each of these sub-processes are extensive areas of research within their own right. However, the focus of this paper is just the knowledge retention aspect of the KM cycle.

Arif et al. (2009) have developed a model to assess knowledge retention in an organisation. The model is depicted in figure 1 below. The reason this model has been selected is due to the

Arif, $\mathrm{M}$ et al. (2012) 'Assessing knowledge retention in construction consultancies: Cases from the UAE', Australasian Journal of Construction Economics and Building, 12 (2) 55-71 
fact that this model was developed specifically for the construction companies in the UAE. Due to this specific application to the country and sector, we decided to apply this model.

This model draws from the work of Nonaka and Takuchi (1995) on SECI model. The SECI model deals with processes involved in making tacit knowledge explicit, hence steps 1 and 2 in the figure. However, the model used in this paper takes the concept of SECI model two steps further. The first one is the process of saving the knowledge in an IT system which can facilitate the retrieval, reuse and updating of knowledge after its future use, hence steps 3 and 4 in the figure. The classic definition of knowledge proposed by Davenport and Prusak (1998) is "a fluid mix of framed experience, values, contextual information, and expert insight that provides a framework for evaluating and incorporating new experiences and information. It originates and is applied in the minds of knowers. In organizations, it often becomes embedded not only in documents or repositories but also in organizational routines, process, practices, and norms." In this paper we want to take this definition forward and define knowledge retention as a formalized process of elaborating, extracting, storing and retrieving knowledge to facilitate informed decision making.

The first step involves socialization and sharing knowledge at individual level. Individuals are important not only because they themselves, are a source of retained information, but also because they largely determine what information will be acquired and then retrieved from other's memory. Nonaka (1994) argue that knowledge in an organisation is created at an individual level. Walsh and Ungson (1991) consider individuals as an excellent starting point for examining information acquisition, retention and retrieval processes.

According to Mckenna (2006) there are two types of knowledge; one tacit and the other explicit. Tacit knowledge is composed of an accumulation of experience in the form of insight and wisdom, which the person may have difficulty in communicating to others but can easily utilise in the performance of a particular task. By contrast, the explicit knowledge lends itself to codification or classification and can easily be expressed. "The explicit knowledge created, should be a strong reflection of best practice within the alliance group, should exhibit shared ownership, and should be able to be easily understood outside its linguistic, organizational and cultural context" (Rice and Rice, 2005). Some of the factors that contribute to sharing tacit knowledge within an organisation are teamwork (Nonaka, 1994) and face to face communication (McManus et al, 2003). Renewing knowledge is another concept that comes from sharing the knowledge. New knowledge is created by people who share and transfer their knowledge and expertise throughout the organisation from individual to individual, individual to a team or group, team or group to individual, or team or group to team or group (Bender and Fish 2000).

Syed-Ikhsan and Rowland (2004) argue that Knowledge transfer requires the willingness of a group or individual to work with others and share knowledge to their mutual benefit. So the effectiveness of a knowledge retention system rests very strongly on how willing people are to socialize and how the organisation facilitates the process of socialization. Organizations can facilitate this step of socialization by organising meetings, events, and providing opportunities to virtually socialise using newer web 2.0 technologies such as twitter or facebook.

The second step in the knowledge retention process is called codification, where the tacit knowledge is converted into explicit knowledge. Patel et al. (2000) define explicit Knowledge as the most common type of knowledge. It is 'readily available' and can be codified and structured in a way that makes it easily transmissible. It is the kind of knowledge that is recorded, and allows people to find it and use it. It can be found in a range of diverse sources, such as human

Arif, $\mathrm{M}$ et al. (2012) 'Assessing knowledge retention in construction consultancies: Cases from the UAE', Australasian Journal of Construction Economics and Building, 12 (2) 55-71 
resources data, meeting minutes and the Internet. They define tacit knowledge as being hard to articulate with formal language as it is personal knowledge embedded in individual experience and involves intangible factors such as personal belief, perspectives, and values. Rice and Rice (2005) argue that in order to effectively capture the tacit knowledge into explicit form, creative and varied range of compilation and storage systems are vital. What is really important is to capture tacit knowledge in an explicit form without losing the context. We do accept that not every piece of tacit knowledge can be converted into explicit form, and we might not be able to do much about it. But what we can do, is to maximize the conversion as much as we can. One thing we can do to enhance the efficiency of knowledge capture is to capture it in multiple formats. Some knowledge might be more effectively captured if it is stored in the form of video or voice of the owner of the knowledge, and maybe converting it into a text file will result in loss of some of the context of the knowledge. So the conversion from tacit to explicit form should not be just in the form of a text file but should have multiple types of files that can potentially add context to the knowledge. This step can be facilitated by providing IT repositories and databases that are easily searchable.

The third step is the process of combination. In this process the knowledge is captured into organisational memory. In order to construct an organisational memory we need to first understand the roles it plays. According to Walsh and Ungson (1991) a consideration of organisational memory reveals that it plays three important roles within the organisation. First, it plays an informational role; the information content that is housed in memory's retention facilities can contribute to efficient and effective decision making. Second, organisational memory fulfils a control function; it can reduce the transaction costs that are often associated with the implementation of a new decision. Third, organisational memory can play a political role. Walsh and Ungson (1991) suggest five storage bins for retention facilities; individuals, culture, structure, transformation and ecology. McManus et al. (2003), argue that the knowledge must be arranged in an organised coherent or systematic form, and that the determination of how to properly package the knowledge so that it can be available when and where needed based on necessity, is critical. Future knowledge in the form of data and information can be stored in a variety of ways with access for all employees. It is also transferred in various ways such as e-mail, groupware, Internet, intranet, and videoconferencing. In this sense, information technology should be seen as a necessary tool, but technology and its use is not in itself knowledge management or indeed knowledge transfer (Bender and Fish, 2000).

The fourth step in the knowledge retention process is knowledge retrieval. Walsh and Ungson (1991), state that there are two concerns of knowledge retrieval. The first is the kind of events or circumstances that trigger the controlled search for information from memory. The second is how the various organisational attributes moderate the response to such triggering stimuli. At the organisational level, one example of automatic retrieval occurs when present behaviours are based on previous practices and procedures that have been shared and encoded in transformations, role structure, culture, and workplace ecology. Gammelgaard and Ritter (2005) argue that the retrieval consists of search and decoding processes. Search is the process by which retained information is selected as relevant to a particular problem or goal. Decoding is the reconstruction of the selected information to satisfy the user's request. It is, therefore, useful to divide the retrieval process into two steps: the identification of knowledge, and the receivers' individual decodification of the accessed knowledge. The filtering of particular information from memory that supports a particular agenda can serve as a means to enhance and sustain power (Walsh and Ungson, 1991). The knowledge management system must incorporate the ability to adapt to new knowledge so that it can be refreshed (McManus et al., 2003). The retrieved knowledge will be updated by the user and the updated knowledge has to be again captured into the system. In order to facilitate this step of internalisation, the system should have the

Arif, $\mathrm{M}$ et al. (2012) 'Assessing knowledge retention in construction consultancies: Cases from the UAE', Australasian Journal of Construction Economics and Building, 12 (2) 55-71 
capability of codify and decodify using keywords. It should be in-built into the culture of the organisation to codify, store and then search the existing knowledge before one tries to create new knowledge. The four steps are shown in Table 1. Based on these four steps of knowledge retrieval process, we can specify four levels that indicate the maturity of an organisation in knowledge retention. The four levels and their characteristics are specified in table 1 . The four levels are:

Level-1: The knowledge is shared amongst the organisation employee.

Level-2: The shared knowledge is documented (transferred from tacit to explicit)

Level-3: The documented knowledge is stored.

Level-4: The stored knowledge is accessible, can be retrieved and used easily.

\begin{tabular}{|c|c|c|c|c|c|}
\hline \multicolumn{2}{|c|}{ Requirements } & \multirow{2}{*}{$\begin{array}{l}\text { Level-1 } \\
\text { Shared at } \\
\text { Individual level } \\
\text { How often meetings } \\
\text { are held? }\end{array}$} & \multirow{2}{*}{$\begin{array}{l}\text { Level } 2 \\
\text { Codified/ } \\
\text { Documented } \\
\text { Are they } \\
\text { minuted? }\end{array}$} & \multirow{2}{*}{$\begin{array}{l}\text { Level } 3 \\
\text { Stored/ } \\
\text { retained } \\
\text { Are they stored? } \\
\text { If yes, where? }\end{array}$} & \multirow{2}{*}{$\begin{array}{l}\text { Level } 4 \\
\text { Retrieved/ } \\
\text { Used }\end{array}$} \\
\hline $\begin{array}{l}\text { Face-to-face } \\
\text { communication } \\
\text { meetings } \\
\text { (formal and } \\
\text { informal) }\end{array}$ & $\begin{array}{l}\text { Nonaka } \\
\text { (1994)and } \\
\text { Newell et al. } \\
(2006)\end{array}$ & & & & \\
\hline $\begin{array}{l}\text { Sharing thinking } \\
\text { process: brain } \\
\text { storming session }\end{array}$ & $\begin{array}{l}\text { Nonaka } \\
\text { (1994) }\end{array}$ & $\begin{array}{l}\text { How are problem } \\
\text { solved?(individually/ } \\
\text { collectively) }\end{array}$ & $\begin{array}{l}\text { Are the } \\
\text { problems and } \\
\text { solutions } \\
\text { recorded? }\end{array}$ & $\begin{array}{l}\text { Is it stored? If } \\
\text { yes, where? }\end{array}$ & $\begin{array}{l}\text { Is it accessible? } \\
\text { Is it retrievable? }\end{array}$ \\
\hline $\begin{array}{l}\text { Lessons learnt } \\
\text { (at the end of the } \\
\text { project phases, or } \\
\text { at the handing } \\
\text { over?) }\end{array}$ & & $\begin{array}{l}\text { Is the project } \\
\text { problems discussed } \\
\text { at the end? }\end{array}$ & $\begin{array}{l}\text { Are those } \\
\text { lessons learnt } \\
\text { documented? }\end{array}$ & $\begin{array}{l}\text { Where is it } \\
\text { stored? }\end{array}$ & $\begin{array}{l}\text { Are people } \\
\text { aware of its } \\
\text { existence? }\end{array}$ \\
\hline $\begin{array}{l}\text { Job rotation } \\
\text { (between } \\
\text { different branches } \\
\text { in different cities } \\
\text { and countries) }\end{array}$ & $\begin{array}{l}\text { Bender and } \\
\text { Fish }(2000)\end{array}$ & $\begin{array}{l}\text { Does the org. } \\
\text { support job rotation } \\
\text { system? }\end{array}$ & $\mathrm{N} / \mathrm{A}$ & $N / A$ & $N / A$ \\
\hline $\begin{array}{l}\text { Renewing } \\
\text { knowledge }\end{array}$ & $\begin{array}{l}\text { Bender and } \\
\text { Fish (2000) }\end{array}$ & $\begin{array}{l}\text { Is the retrieved } \\
\text { knowledge } \\
\text { discussed before } \\
\text { using? }\end{array}$ & $\begin{array}{l}\text { Are the } \\
\text { feedback / new } \\
\text { knowledge } \\
\text { documented? }\end{array}$ & $\begin{array}{l}\text { Is the stored } \\
\text { knowledge } \\
\text { updated? }\end{array}$ & $\begin{array}{l}\text { Is the updated } \\
\text { knowledge } \\
\text { accessible? }\end{array}$ \\
\hline $\begin{array}{l}\text { Self organised } \\
\text { teams }\end{array}$ & $\begin{array}{l}\text { Nonaka } \\
\text { (1994) }\end{array}$ & $\begin{array}{l}\text { Do they exist? Is } \\
\text { trust among } \\
\text { employees built? }\end{array}$ & $\begin{array}{l}\text { Is the created } \\
\text { knowledge and } \\
\text { ideas } \\
\text { documented? }\end{array}$ & $\begin{array}{l}\text { Is it stored? If } \\
\text { yes, where and } \\
\text { how? }\end{array}$ & $\begin{array}{l}\text { Is it accessible? } \\
\text { Do people know } \\
\text { how to retrieve } \\
\text { it? }\end{array}$ \\
\hline $\begin{array}{l}\text { Training and } \\
\text { coaching } \\
\text { system }\end{array}$ & & $\begin{array}{l}\text { Are trainings held } \\
\text { regularly? }\end{array}$ & $\begin{array}{l}\text { Are the } \\
\text { trainings / new } \\
\text { knowledge } \\
\text { documented? }\end{array}$ & $\begin{array}{l}\text { Are they stored? } \\
\text { If yes, where } \\
\text { and how? }\end{array}$ & $\begin{array}{l}\text { Is the training } \\
\text { manual } \\
\text { accessible for } \\
\text { all employees? }\end{array}$ \\
\hline $\begin{array}{l}\text { Competition and } \\
\text { award system }\end{array}$ & & $\begin{array}{l}\text { Is there any award } \\
\text { for knowledge } \\
\text { sharing? }\end{array}$ & $\begin{array}{l}\text { Is there any } \\
\text { award for } \\
\text { documenting } \\
\text { knowledge? }\end{array}$ & $\begin{array}{l}\text { Is there a } \\
\text { system allows } \\
\text { people to store } \\
\text { documents? }\end{array}$ & $\begin{array}{l}\text { Is it accessible? } \\
\text { Is it retrievable? }\end{array}$ \\
\hline
\end{tabular}

Table 1 Levels of Knowledge Retention in an Organisation

This paper uses the framework described above and documented in figure 1 to present three case studies of multinational construction consultancies in the UAE. Since these are multinational companies, they have maintained mostly similar processes worldwide with some influence of the UAE culture. Therefore, the practices highlighted in these studies can easily be adapted for other countries. The next section describes the methodology used for collecting

Arif, $\mathrm{M}$ et al. (2012) 'Assessing knowledge retention in construction consultancies: Cases from the UAE', Australasian Journal of Construction Economics and Building, 12 (2) 55-71 
data for compiling these case studies. This section is followed by the section containing the three cases.

\section{Methodology}

In order to capture the knowledge retention practices the framework described in the previous section was applied to three case-studies of multinational construction consultancies in the UAE. A case study is defined as a strategy for doing research which involves an empirical investigation of a particular phenomenon within its real life context, especially when the boundaries between phenomenon being studied and the context within which it is being studied are not clearly evident (Yin, 2003). This method of study is especially useful for trying to test/validate theoretical models by using them in real world/organisation situations, and testing whether scientific theories and models actually work in real life. The method of data collection was semi-structured interview. As Fellows and Liu (2003) argued, semi-structured interviews fill the spectrum between the structured and the unstructured extremes. The purpose of doing the interview is to get a wider picture and more detailed information about the knowledge sharing process and practices. Moreover, it allows for non-verbal communication or body language which has an impact on the responses. For the purpose of this study the three largest multinational construction consultancies were selected. Three people each were interviewed in the three organisations we will call Companies A, B, and C. Out of the three employees in each of our participating organizations, one was the regional manager, and the other two employees were design engineers (See Table 2). As part of the study, we also elicited the views of 30 employees each from each of those three organisations. Although the data from these surveys are reported elsewhere, the views from the respondents of the questionnaires corroborate the views from the three interviewees. The interviews took place in each employee's office. Although there were no time constraints, it took between 45 minutes and one hour to complete the interviews. Each participant was apprised of the relevance of the study and the structure of the knowledge retention model. All of them were also provided with printouts of Figure 1 and Table 1.

\begin{tabular}{|c|l|l|c|c|c|}
\hline \multicolumn{1}{|c|}{ Position } & \multicolumn{1}{c|}{$\begin{array}{c}\text { Education } \\
\text { COMPANY A }\end{array}$} & $\begin{array}{c}\text { Duration } \\
\text { with }\end{array}$ \\
\hline \multicolumn{2}{|c|}{} & \multicolumn{1}{|c|}{ Company } \\
\hline 1 & Regional Manager & PhD & 30 & 15 \\
\hline 2 & Design Engineer & Bachelors & 5 & 5 \\
\hline 3 & Design Engineer & Bachelors & 9 & 4 \\
\hline & \multicolumn{1}{|c|}{ COMPANY B } \\
\hline 1 & GCC Manager & Masters & 35 & 12 \\
\hline 2 & Design Engineer & Bachelors & 8 & 8 \\
\hline 3 & Senior Design Engineer & Masters & 12 & 5 \\
\hline & & \multicolumn{1}{|c|}{ COMPANY C } & 11 \\
\hline 1 & Regional Manager & Masters & 27 & 3 \\
\hline 2 & Design Engineer & Bachelors & 6 & 4 \\
\hline 3 & Design Engineer & Bachelors & 8 & \\
\hline
\end{tabular}

Table 2 Interviewee profile

This was done in order for the respondents to put their thoughts in the context of the model. The questions asked are documented in Appendix A. The questions were not asked in a specific order, flexibility was given to people, to talk without much restriction of rigid question

Arif, $\mathrm{M}$ et al. (2012) 'Assessing knowledge retention in construction consultancies: Cases from the UAE', Australasian Journal of Construction Economics and Building, 12 (2) 55-71 
order or check lists. This flexibility gave the chance for people to explain in detail, the system they have in their companies. In addition, if they had any IT system, forms or processes related to Knowledge management, they were asked to show them to the researchers.

\section{Case Studies}

\section{Company A}

Company $\mathrm{A}$ is a multi-disciplinary construction and architectural engineering consultancy firm and is regarded as one of the top 5 in the world in terms of size and revenues. It has 200 different offices around the world; and performs activities in a wide spectrum of construction engineering areas, spanning from design and architecture to procurement and construction management. It has around 17000 employees worldwide, 2000 of them are based in Middle East and 1200 are UAE based.

It has been realised through the interviews that Company A does encourage communication through a variety of meetings and special activities such as 'Architectural Fridays', 'Excellence awards' and 'Mentoring sessions'. Everyone agreed that face-to face communication both formally and informally is encouraged and an environment exists where people talk freely to each other, irrespective of their position in the company, a culture that interviewees attributed to a flat organizational structure. However, only formal periodic department and project update meetings are minuted. Company A has a very well structured and formal mentoring programme which encourages teamwork and knowledge sharing between individuals (both senior and junior staff). The organisation encourages team problem solving and, often, decisions on projects are taken, based on views from different employees involved. Several project and departmental improvement programmes involve brainstorming sessions where the session procedures and outcomes are documented and circulated. Post project review documents are required by all project managers after each project, and they are saved on an intranet based database. However, there have been instances where people have retrieved older documents from past projects and have realized that the practices and technology used in those projects are outdated, yet no one has updated it; hence on several occasions employees have found the past information of very little help. However, Company A management does encourage employees to ensure that the information from the past they will be using on their projects, is valid for the situation, or if it needs to be updated, they do end up updating it after their project is complete. Anyone updating the information needs to ensure that it is saved as the latest version of the older information and is properly archived and documented in order to ease the process of retrieval of any version of information (latest or older) by users in the future.

Company A strongly supports the idea of job rotation and it is part of its policy. Sometimes, however, and due to the lack of resources, the managers are reluctant to release their good employees and send them somewhere else. Each employee is entitled to attend three training programmes per year, and training manuals as well as advertisements for future training programmes are stored at a Company library so employees can access them anytime. But a significant majority of training programmes are primarily focused on developing softer skills, some engineers and designers realize that they are able to develop softer skills through these training programmes but their technical skills become obsolete with time due to lack of these training programmes. People who update their technical skills through graduate programmes do not conduct any formal training or dissemination for other colleagues as their own graduate degrees are not funded by the company. So most of them regard going for advanced technical degrees in construction as personal fulfillment and enrichment, more than organizational development. The company has some programmes for encouragement of voluntary knowledge sharing. "Rising Star Programme" is a competition of innovative ideas, where all employees can participate with their own ideas. Those ideas are then evaluated and selected for further review

Arif, $\mathrm{M}$ et al. (2012) 'Assessing knowledge retention in construction consultancies: Cases from the UAE', Australasian Journal of Construction Economics and Building, 12 (2) 55-71 
by a team of managers. Each candidate then prepares a poster explaining their ideas and all the relevant knowledge associated with it. The topics can be either about any relevant technical, management or environmental issue. The winners are awarded cash prizes. Through this programme, good ideas are collected and archived in the company intranet based system. People in the architecture department also share their ideas through "Architectural Fridays". In each of "Architectural Fridays" session, an architect prepares and presents a power point presentation, and then the subject is discussed. This gives opportunity for people to present their ideas, share it, discuss it and get feedback from other employees. There are regular meetings at managerial level also, where knowledge is shared across department and these meetings are minuted and the minutes, archived. There are also formally organized knowledge sharing sessions. A call goes out to invite presenters to come and share their experiences from a recent project or company activity, two weeks prior to the session. Whoever volunteers, then has to do a PowerPoint presentation in front of all the employees of the organization at that location. This presentation is then archived on the intranet-based database.

The knowledge archiving system used is a database that is accessible from the company intranet. At the moment, the database is still being populated. An extensive document management system is being added to this system in order to access drawings and other project documents from the past. A project to enhance the system to store and facilitate retrieval of all forms of information (data, documents, drawings, audio, and video clips) is underway and has 30 people working full time to operationalise as well as populate the system with all the past information. The knowledge sharing, intranet-based system, once completed will also have the capability to start a chatroom session with any other employee and archive the conversation in the database. Once the intranet-based system is fully operational, it will contain the files and library used to produce designs and drawings, feedback reports classified by project (name or code) and by project type, technology review papers, design solutions, specifications and the organisation's standard ways of solving problems. It would also contain such files as British engineering and architectural standards (as these are the ones followed in the UAE), introduction booklets of projects and technologies, notes for unusual jobs and experiences, and knowledge related to sustainability as well as green design, training manuals, presentations from employees, training videos and all formal departmental and project meeting minutes. The system currently is, and in the future as well will remain accessible to all employees except some confidential financial data, which will be accessible to people with some level of internal clearance. There is a library on the premises that houses hardcopies or manuals and training booklets, videos and DVDs. There is also a document management service that stores hardcopy drawings and other technical documents from past projects. Most of these repositories will be incorporated on this intranet-based system over the next few years.

This is a huge project and some of the main difficulties facing the project include: the amount of time and effort required to populate the database, the perception among employees that once this system is operational the amount of time spent by employees in documenting lessons learnt would be significant; and sooner or later with aggressive project deadlines people may start to ignore the system altogether, and would there be an incentive for employees to use this system since this would be extra work for them? Two of the employees interviewed were not sure how the time required for feeding and retrieving the information would be accounted for. Would it be budgeted into projects like current post project review, or would it be charged to the overhead account? However, one of the interviewees who is a senior manager assured us that the company is aware of these issues and is trying to devise procedures and practices to alleviate these concerns. All three employees were asked to rate the organization currently and they all felt that it was between levels two and three. They all said that almost formal meetings are documented, and a majority of them are stored as well, but quite often with pressing project

Arif, $\mathrm{M}$ et al. (2012) 'Assessing knowledge retention in construction consultancies: Cases from the UAE', Australasian Journal of Construction Economics and Building, 12 (2) 55-71 
deadlines the storage process takes a back seat. The other reason why they wanted to rate the current system a notch below level three is due to the fact that the past information is still being populated on the intranet-based database. Once the intranet based system is completely populated, the status will move to above level three, where the information is documented and stored. For it to become a level four organization, a wider practice of use of the system, both for feeding the experience and conducting research prior to starting a new project, will have to prevail. In order to do that an elaborate value marketing of the system among employees will have to be conducted. Once employees are informed about the usage and value of the system, the participation rate would be definitely higher. Some sort of incentive for using the system can also potentially increase the usage. The incentive could be a reward system for submission, or recognition for using and updating past knowledge.

\section{Company B}

Company B is an Engineering and Project Management consultancy. It provides consultancy and project management services in the fields of: transport, highways, building, land development, telecommunications, health and education. It has around 4000 employees worldwide, 1050 of them are based in Middle East and 450 are UAE based.

The atmosphere in the company is quite casual and the organizational structure quite flat. So employees feel at ease communicating both formally and informally with employees from their own as well as other departments at all levels. Formal meetings are minuted. There are no special events or initiatives like the ones in Company A for knowledge sharing. All the sharing takes place either at an informal level or through formal project and departmental meetings. However, the culture in the organization is such that all the problems in the area of management, engineering, or people issues are solved through formal process improvement initiatives driven primarily by top management. Lower and middle managers have to seek higher approval and buy-in, prior to any process improvement initiative. Monthly reports are circulated among all employees on progress made in different projects, and any other ongoing initiatives in the company. However, they are not stored on any searchable database which is easily and remotely accessible. Each departmental manager is responsible for managing the knowledge in his department, in terms of making knowledge and experiences from the past accessible to at least employees from their own department but this knowledge repository is nothing more than a folder with hardcopy files which has minutes and reports arranged in a chronological or alphabetical order. Other than the manager itself, very few employees access them. Job rotation is acknowledged as a very important issue but is not practiced frequently. In some projects that require specific skills, people are seconded for a few weeks or months and then they come back to their parent department.

Each employee is entitled to one training programme a year and the organization has the online subscription for Harvard Business Review. The company also has subscription to the ELearning module of Harvard, where employees can enroll in online training programmes. Company $B$ has recognized the lack of knowledge management system and has started on an initiative to develop an in-house system. A global knowledge manager has been appointed who is based in the UK. In addition, a knowledge champion has been appointed in each region. The company has an email system for each country it has offices in, and the servers of all the global locations are connected. There exists a document management system in each country where one can retrieve drawings and technical documents of different projects. The company is currently in the process of establishing an intranet knowledge management system based on Microsoft Sharepoint ${ }^{\mathrm{TM}}$ Platform. This intranet based system will have eight components. The first one will have information about the company globally, regional information about best practices, bidding, project management, organizational structure, human resource plan, skills,

Arif, $\mathrm{M}$ et al. (2012) 'Assessing knowledge retention in construction consultancies: Cases from the UAE', Australasian Journal of Construction Economics and Building, 12 (2) 55-71 
job description, marketing plans and procedure, and intranet usage guide. The second part of this system will be a standards library, which will contain technical and regulatory standards globally and regionally. The third part of this system will be a news portal publishing global and regional monthly employee magazines and archiving them. The fourth part of the system information on job description, available skills, required skill, and will also incorporate the current Harvard E-Learning module. The fifth part will have commercial data, regarding past bids, financial data, profit statements and projections. This part of the system will be accessible by people only at a certain level of management. The sixth component will have HR related information regarding vacation for each employee, timesheets, payroll, and project spending on monthly and weekly basis. The seventh component will have some standards guidelines type of documents, like guides on writing project bids, project strategies, departmental strategies, CVs etc. The last component of this system will have a place for managers to store departmental and project meeting minutes.

Currently, this system is being implemented and training for the system is being planned. However, we could not get information about any timeframe planned for this system's implementation despite probing. Currently, procedures and protocols are also being put in place to ensure proper usage and updating of this system. The organisation can be evaluated between levels one and two of the maturity model. Where there are meetings and informal knowledge sharing opportunities but not everyone stores and archives knowledge.

\section{Company C}

Company $\mathrm{C}$ is a Consultancy firm specializing in planning, design and management services for infrastructure development. It employs 6000 people in more than 70 countries, 1200 of them are based in the Middle East region and 900 in UAE.

Company $\mathrm{C}$ encourages communication both formal and informal within a department, but to communicate with other departments, one has to go through their line manager. Formal departmental and project meetings are minuted and circulated among all participants. Like Company $\mathrm{B}$, in Company $\mathrm{C}$ as well, the major process or system improvement initiatives are let by higher level management. There is a knowledge management system that has information on global best practices, lessons learnt, and technical standards. But very few people in the UAE were aware of the existence of this system. The current system is primarily driven and maintained by the UK office of the organization. Although, other offices have access to this system, they know very little about it. Practices like job rotation do not exist. But employees are often seconded to other locations for short periods of time. Each employee gets to attend one training programme a year on technical issues. Several in-house training programmes for management skills improvement are available through an in-house e-learning system.

Company $\mathrm{C}$ has an extensive intranet based knowledge management system with seven components. The first component is the news and bulletin board, where the monthly employee magazine for the company is placed in soft form. There is one more monthly magazine which has articles and updates on project progress and client relations. This magazine is also available on in this section. The second component of this system is the client information section. In this section, information regarding all the existing clients and a history of past and present projects is stored. The third component has information about the organizational structure, vision, mission, and business principles of organization. This component also has the overall organizational structure as well as organizational structure of its five business groups. Under each business group there is information about business development, management, resources, skill groups, training, finance and operation. The fourth component is the business development system. This section has information on past bids and a bidding support system

Arif, $\mathrm{M}$ et al. (2012) 'Assessing knowledge retention in construction consultancies: Cases from the UAE', Australasian Journal of Construction Economics and Building, 12 (2) 55-71 
that helps employees prepare bids for new projects. The fifth component of this system is the employee operational resources repository. This section has guidance and operating principles of the company in the areas of procurement, dispute resolution, expert witness, legal agreements, company statistics, and health and safety guidelines. This component of the system also has lessons learnt system where employees can enter new practices and experiences. This component also has an e-library which has several e-books and reports. The e-learning system described earlier is also a part of this component. The sixth component is the business systems component. Parts of this system have restricted access. This section contains the commission management system which has comprehensive profit and earnings statement for senior management to access and evaluate. This also has information on legal contracts and overview of legal clauses under different kinds of existing contracts. This system also provides facilities utilization information with layouts of all the office spaces. The last component of the system is called the people system. This section contains employee CVs with information about their specific skills, specializations, location etc. This component also has information on job openings, and recruitment, staff surveys, training programme based information and HR procedures.

Based on our discussions with employees we found out that although this system is quite elaborate and extensive; still people do not use it that often. Especially when it comes to the lessons learnt part of the system, not many people use it and update it with their own experiences. Multiple people posting their experiences on the system might use different keywords as there is no monitoring or protocol for the system. There is no training programme available for employees to explain the benefits, and functionality of the system, so most of the employees learn it as they go. There is no incentive or programme that encourages the use of this system either. One of the managers we interviewed did accept that they are aware of the sparse usage of the system and are looking at ways to improve the usage. This system can be rated between levels two and three of our framework, as not all the knowledge that can be stored is being stored and the usage is quite limited.

\section{Discussion and Analysis}

Table 2 presents a summary of the analysis of the three cases presented in this paper. The first column highlights the major criteria used for analysis, and the results of the analysis of the three cases is presented in the cells of the corresponding row.

Out of the three companies analysed in this study, there is one element that is common between them; the element being the use of information technology. Although they all are at different stages of implementation, they all appreciate the value that can potentially be added through the use of technology. However, what is quite different about the three companies is, how they have positioned their IT systems different, strategically. Company A has several knowledge sharing initiatives like architectural Fridays, and rising star award. These initiatives have been going on even before the IT system was conceived and have contributed to building a culture where knowledge sharing occurs and is accorded appropriate recognition. So the culture of sharing the knowledge has been in existence and now the use of technology will further facilitate and enhance this culture. So the role of technology is that of a facilitator. The impact of organizational culture and climate on knowledge sharing and retention has received considerable attention in recent years (Spender, 1996; Nonaka and Takeuchi, 1995). There are different cultural constructs that have been investigated by researchers in knowledge sharing and retention research. In our study we operationalized the impact of culture through planned activities (eg. architectural Fridays, and rising star awards) as well as associated rewards. Companies $\mathrm{B}$ and $\mathrm{C}$ have yet to implement a planned associated activities that arguably contribute to knowledge sharing and retention. Whilst Company $A$ has implemented with

Arif, $\mathrm{M}$ et al. (2012) 'Assessing knowledge retention in construction consultancies: Cases from the UAE', Australasian Journal of Construction Economics and Building, 12 (2) 55-71 
evidence showing that benefits have accrued through these planned activities. Same could be said about the reward systems. For completeness, there are other cultural constructs which this study hadn't addressed, but important to note here for future research. Some of these cultural variables have been identified by Olomolaiye (2007) and include teamwork participation, top management openness for discussions with employees, encouragement of creativity and dynamism (including the notion of a no blame culture) and emphasis on individual initiatives and freedoms. For companies B and C, no such knowledge sharing initiatives exist, and the planned and existing IT systems in those two respective companies are being put in place to store the corporate information, and some knowledge that exists in explicit form. No matter how elaborate these systems are, their ability to encourage someone to convert their tacit knowledge into an explicit form and then storing it, is questionable, to say the least. In both these companies strict lines of communication and top-down nature of most performance improvement initiatives means that a culture of knowledge sharing is not as prevalent, as was the case in Company A. So the knowledge sharing driver in case of company $A$ is the culture, and technology has been used merely as a tool. Whereas, in the other two cases, the sharing of knowledge has been left to a technological initiative, with an assumption that once technology is in place, people will use it. This difference in paradigm is quite significant, and forces us to go back to the debate of what is the role of information technology in the operations of a company. Is it a driver or the facilitator? (Arif et. al, 2005)

Company A also has one more thing in its favor through these knowledge sharing initiatives. Through these initiatives, there is a reward and recognition system in place which provides an incentive for knowledge sharing. A significant body of past research has shown that incentives, rewards, and recognition play a very crucial role in encouraging people to share their ideas (Woodman et al. 1993; Amiable et. al., 1996; Oldham and Cummings 1996; Fairbank and Williams, 2000; Brief and Aldag, 1977; Frese et al, 1999; Carrier, 1998; Recht and Wilderom, 1998; Stenmark, 2000). Availability of such a reward or recognition system, will definitely encourage a culture of knowledge sharing, as discussed above.

One other technology related issue that all three companies have incorporated into their systems is the ability to capture files in multiple formats. As we have mentioned in the past, it is not possible to convert all forms of tacit knowledge effectively into explicit knowledge. The biggest danger in converting tacit knowledge is the use of context (Patel et. al. 1999: 76; Collins 2001a: 72; Collins 2001b: 108; Ambrosini and Bowman 2001: 812-3; Herbig and Büssing 2003: 167; Tsoukas 2003). Sometimes the variation in voice pitch or the facial expressions of the owner might add a different level of context and intensity to the knowledge. Therefore, it is important that if possible, we try to convert not only the content but the context, and by having the ability to capture files in different formats, we do acquire some of that capability. However, we might never be able to get to $100 \%$ effectiveness in conversion of the content with the context, we can definitely improve it.

Out of the three cases, Company $\mathrm{C}$ has a technology platform that is fully operational. However, the usage is quite infrequent due to lack of any training programme. It is very important to have awareness campaigns to highlight the benefits of knowledge sharing leading to organizational knowledge retention and training for people on how to use the available technology platform to share their knowledge as well as use knowledge from the past.

With tight work and project deadlines, and the time involved in documenting, saving and retrieving knowledge it is often possible that employees will overlook the knowledge retention system. Therefore, it is important that top management be committed to the knowledge retention process and have budgetary provisions for charging the time involved in using and

Arif, $\mathrm{M}$ et al. (2012) 'Assessing knowledge retention in construction consultancies: Cases from the UAE', Australasian Journal of Construction Economics and Building, 12 (2) 55-71 
updating the system. Management also needs to encourage employees to use the system more frequently and effectively. Initiatives like emails sent to employees, discussion of knowledge retention system in staff meetings, posters and publicity material about the system placed all over the facility could be some of the initiatives that top management can contribute in and encourage knowledge retention in the organization.

One more issue involved with knowledge retention system is the configuration management. The archiving system needs to have a numbering policy or system in place that archives the files in some sort of chronological order. The other major configuration related issue is the use of keywords, and cataloguing. There needs to be some way to ensure that two people saving knowledge about same issue catalogue it under the same keyword so that future retrieval is easy. In order to ensure that steps like having an administrator for the system monitoring the new entries or a list of keywords in a database is important and will contribute to configuration management and proper cataloguing.

The impact of organizational structure on knowledge retention, can be complex especially when organizational structure can be operationalized into centralization (extent to which authority and decision making is concentrated at the top), complexity (number of occupational specialization and task differentiation), stratification (number of status, layers, or levels), and formalisation (degree of emphasis placed on following rules and procedures in role performance). In our study evidence suggests that the level of centralization in cases $A, B$, and $C$ is low allowing for greater ease in knowledge retention at the unit level. However, for this knowledge retention to be organization wide, the importance of supporting IT system becomes paramount. But in order to take full advantage of this IT system knowledge in its tacit form cannot be used. Conversion to explicit form is an absolute pre-requisite.

In this study the cases analyzed were regional offices of big organizations, and the level of occupational specializations and task differentiation (i.e. engineers, architects, designers) was low hence the impact that task differentiation could have made was minimal. However, it is an issue worthy of note and future in-depth analysis. Olomolaiye (2007) has shown that high levels of task differentiation and occupational specialization could impact negatively on knowledge sharing and retention. Same could be said of organizational stratification. Although the three cases analyzed in this study showed a low level of organizational stratification, further analysis of highly vertical organization is needed for future research. In addition, our study indicates that the degree of emphasis placed on following rules and procedures is low to medium therefore, the probability of success in knowledge retention is higher Olomolaiye, 2007).

In our case studies only Company B is going ahead with a knowledge champion for their system. The role that a knowledge champion plays in knowledge retention and sharing is vital. Such a role helps to embed positive culture and climate for knowledge sharing and retention. $\mathrm{He} / \mathrm{she}$ also acts as an individual with specific responsibilities to make knowledge retention "work". By implication he/she is expected to be conversant with the workings of the IT systems, and should be able to visualize the role of knowledge and its impact on functioning of the organization (Jones et al, 2003; Zhang and Faerman, 2007).

\section{Lessons Learnt For Future Research}

This research has analyzed cases in order to assess the applicability of a knowledge retention model. It would be interesting for future researchers to look at the acceptability of these knowledge retention processes and IT system, and analyze the drivers and barriers from the users perspective. It would also beneficial to document tangible benefits of these systems and ways of measuring those. This documentation of benefits could also be used for making

Arif, $\mathrm{M}$ et al. (2012) 'Assessing knowledge retention in construction consultancies: Cases from the UAE', Australasian Journal of Construction Economics and Building, 12 (2) 55-71 
business cases for investments by organizations in knowledge retention systems. In this paper we have documented some issues highlighting the relationship between the softer, social and technological elements for a knowledge retention system. However, significant research is needed which adopts a multi-methodological approach in studying the complexity inherent in this interplay.

\section{Summary and Conclusions}

The goal of this research paper was to analyze knowledge retention practices and suggest drivers for knowledge retention. In order to analyze the knowledge retention practices a model developed by Arif et al (2009) was used as a framework. This model has four step knowledge retention process. The first step is sharing of tacit knowledge between individuals and groups. The second step is the conversion of tacit knowledge into explicit knowledge. The third step was the storage of this knowledge and the last step was the retrieval and update of the knowledge. The framework also defines four levels of organizational knowledge retention. The level one is when the knowledge is shared amongst the organisation employee. The second level is when the shared knowledge is documented (transferred from tacit to explicit). The third level is when the documented knowledge is stored, and the fourth level is when the stored knowledge is accessible, can be retrieved and used easily. One of the limitations of this paper is that these multiple levels and their specific characteristics described in Table 1 have been proposed by the research team through internal discussions and past experiences. However, they would need to be validated through a more elaborate future study.

Based on the framework, three cases of three construction consultancies in the UAE were analysed. Based on the analysis of the knowledge retention system the major drivers for its successful implementation are prevalence of a culture of sharing knowledge, reward and recognition for sharing knowledge, a technology platform that can accommodate multi formats of files, awareness of knowledge retention system and its benefits among its employees, and top management support. The knowledge retention approach presented in this paper is holistic in nature and the authors contend that it should be an important addition to the Nonaka and Takuchi (1995) knowledge management process. The study findings reveal the importance of motivation, leadership support, creation of appropriate platforms/infrastructure will create a conducive environment for knowledge retention. Although this list of drivers is not exhaustive, with more cases, future research and additional analysis more drivers will be highlighted. But still, this paper has made some significant observations that can be used to take the research in the area of knowledge retention forward.

\section{References}

Alavi, M. and Leidner, D. (2001) 'Review: knowledge management and knowledge management systems: conceptual foundations and research issues', MIS Quarterly, 25 (1), 107-36

Alom, O. (2007) Knowledge Retention in Construction Consultancies in the UAE, Unpublished Masters Dissertation, Institute of Engineering, The British University in Dubai, UAE

Amabile, T. M., Regina C., Heather, C., Lazenby, J., and Herron, M. (1996) 'Assessing the work environment for creativity', Academy of Management Journal, 21 (5), 1154-1184

Ambrosini, V. and Bowman, C. (2001) 'Tacit knowledge: Some suggestions for operationalization', Journal of Management Studies, 38 (2), 811-829

Arif, M., Egbu, C., Alom, O., and Khalfan, M. (2009) 'Measuring knowledge retention: a case study of a construction consultancy in the UAE', Engineering Construction and Architecture Management, 16 (1), 92-108

Arif, $\mathrm{M}$ et al. (2012) 'Assessing knowledge retention in construction consultancies: Cases from the UAE', Australasian Journal of Construction Economics and Building, 12 (2) 55-71 
Bender, S. and Fish, A. (2000) 'The transfer of knowledge and the retention of expertise: the continuing need for global assignments, Journal of Knowledge Management, 4 (2), 125-137

Brief, A. P., and Aldag, R. J. (1977) 'The Intrinsic-Extrinsic Dichotomy: Toward Conceptual Clarity', Academy of Management Review 2 (3), 496 - 499

Carrier, C. (1998) 'Employee Creativity and Suggestion Programs: An Empirical Study', Creativity and Innovation Management 7 (2), 62-72

Collins, H.M. (2001a) 'Tacit knowledge, trust, and the Q of sapphire', Social Studies of Science, 31 (1), 71-85

Collins, H.M. (2001b) 'What is tacit knowledge?' In: Schatzki, T.R., Knorr Cetina, K. and von Savigny, E., (Eds.) The practice turn in contemporary theory, Routledge, London and New York, 107-119

Davenport, T. H., and Prusak. L. (1998) Working Knowledge: How Organizations Manage What They Know, Harvard Business School Press, Cambridge, MA

Egbu, C. (2006) 'Knowledge production and capabilities - their importance and challenges for construction organisations in China', Journal of Technology Management in China, 1 (3), 304321

Fairbank, J.F., and Williams, S.D. (2001) Motivating Creativity \& Enhancing Innovation through Employee Suggestion System Technology, Creativity and Innovation Management, 10 (2), 6874

Fellows, R. and Liu, A. (2003) Research Methods for Construction, $2^{\text {nd }}$ ed, Blackwell Science Ltd, Oxford, UK

Fong, P.S.W. and Choi, S.K.Y. (2009) 'The processes of knowledge management in professional services firms in the construction industry: a critical assessment of both theory and practice', Journal of Knowledge Management, 13 (2) 110-26

Frese, M., Eric, T., and Cees, J. D. (1999) 'Helping To Improve Suggestion Systems: Predictors of Making Suggestions In Companies', Journal of Organizational Behaviour, 20 (7), 1139-1155

Gammelgaard, J. and Ritter, T., (2005) The knowledge retrieval matrix: codification and personalisation as separate strategies, Journal of Knowledge Management. 9 (4), 133-143.

Gurteen, D. (1998), 'Knowledge Management and Creativity', Journal of Knowledge Management, 2 (1), 25-37

Herbig, B. and Büssing, A. (2003) 'Comparison of the role of explicit and implicit knowledge in working', Psychology Science, 45 (2) 165-188

Jones, B.N; Herschel. R.T and Moesel, D.D. (2003) 'Using Knowledge champions to facilitate knowledge management', Journal of Knowledge Management, 7 (1), 49 - 63

Kamara, J.M., Augenbroe, G., Anumba, C.J. and Carrillo, P.M. (2002) 'Knowledge management in the architecture, engineering and construction industry', Construction Innovation, 2 (3), 53-67

Kim, S. and Lee, H. (2010) 'Factors Affecting Employee Knowledge Acquisition and Application Capabilities', Asia-Pacific Journal of Business Administration, 2 (2), 133-152

Mckenna, E. (2006) Business Psychology and Organisational Behaviour: A student's handbook, 4th ed, Psychology Press, East Sussex

McManus, D. J., Wilson, L. T. and Snyder, C. A. (2003) Assessing the business value of knowledge retention projects: results of four case studies, Available at: http://www.knowledgeharvesting.org/documents/Assessing\%20the\%20Business\%20Value\%20 of\%20Knowledge\%20Retention\%20Projects.pdf [accessed on 29/01/07]

Arif, $\mathrm{M}$ et al. (2012) 'Assessing knowledge retention in construction consultancies: Cases from the UAE', Australasian Journal of Construction Economics and Building, 12 (2) 55-71 
Newell, S., Bresnen, M., Edelman, L., Scarbrough, H. and Swan, J. (2006), 'Sharing knowledge across projects: limits to ICT-led project review practices', Management Learning, 37 (2), 16785

Nonaka, I. (1994) 'A Dynamic Theory of Organizational Knowledge Creation', Organisation Science, 5 (1), 14-37

Nonaka, I., and Takeuchi, H. (1995) The Knowledge Creating Company, Oxford University Press, Oxford

Oldham, G. R. and Cummings, A. (1996) 'Employee Creativity: Personal And Contextual Factors At Work', Academy of Management Journal, 39 (3), 607 - 634

Olomolaiye, A.O. (2007) The Impact of Human Resource Management on Knowledge Management For Performance Improvements in Construction Organisations, Unpublished Doctoral Thesis, School of Built and Natural Environment, Glasgow Caledonian University

Patel, M., MeCarthy, T.J., Morris, P.W.G. and Elhag, T.M.S. (2000) The role of IT in capturing and managing knowledge for organisational learning on construction projects, Centre for research in the management of projects (CRMP), UMIST,UK

Recht, R., and Wilderom, C. (1998) 'Kaizen And Culture: On The Transferability Of Japanese Suggestion Systems', International Business Review, 7 (1), 7- 22

Rice, J. L. and Rice B. S. (2005) 'The applicability of the SECI model to multi-organisational endeavours: An interactive review', International Journal of Organisational Behaviour, 9 (8), 671-682

Spender, J.C. (1996) 'Making knowledge the basis of a dynamic theory of the firm', Strategic Management Journal, 17 (1), 45-62

Stenmark, D. (2000) Company-wide brainstorming: Next Generation Suggestion Systems?, Proceedings of IRIS 23, Laboratorium for Interaction Technology, University of Trollhättan Uddevalla, [online], Available: www.viktoria.se/results/result files/141.pdf [Accessed 5 June, 2006]

Syed-Ikhsan, S.O.S. and Rowland, F. (2004) Knowledge management in a public organisation: a study on the relationship between organisational elements and the performance of knowledge transfer, Journal of Knowledge Management, 8 (2), 95-111

Tsoukas, H. (2003) 'Do we really understand tacit knowledge?' In: Easterby-Smith, M. and Lyles, M.A., (Eds.) The Blackwell Handbook of Organizational Learning and Knowledge Management, Blackwell Publishing Ltd, Malden, MA; Oxford, 410-427

Walsh, P. J. and Ungson, G. (1991) 'Organisational memory', The Academic of Management Review, 16 (1), 57-91

Woodman, R. W., Sawyer, J. E. and Griffin, R. W. (1993) 'Toward A Theory Of Organizational Creativity', Academy of Management Review 18 (2), 293 - 321

Yin, R.K. (2003) Applications for Case Study Research, $2^{\text {nd }}$ ed, Sage, London

Zhang, J. and Faerman S. R. (2007) 'Distributed leadership in the development of a knowledge sharing system', European Journal of Information Systems, 16 (4), 479-493 


\section{Appendix A}

1. Can you give me a brief about the existing system of knowledge management in the company?

2. What types of knowledge you can find in the system? (Technical, meeting, lessons learnt)

3. System characteristics:

a. ability to retrieve knowledge

b. type of knowledge documented

c. awareness of what is really documented

d. usefulness of the information documented

e. time consuming (documenting and searching)

f. Accessibility

4. How do you deal with the problem of loosing knowledge of people who leaves the company (retirement, resignation)? Does the existing system support the retention of employee's knowledge?

5. Are you satisfied with it?

6. How often the employees get trainings? Is there is any place where the company training manuals are stored?

7. At what level do you classify knowledge sharing in your organization, and why? 